\title{
Effect of Absorber Layer Thickness on the Performance of Bismuth-Based Perovskite Solar Cells
}

(C) U.C. Obi ${ }^{1}$, D.M. Sanni ${ }^{2,3}$, A. Bello ${ }^{1,2,9}$

${ }^{1}$ Department of Material Science and Engineering, African University of Science and Technology (AUST), P.M.B. 681 Garki, Abuja, Nigeria

${ }^{2}$ Department of Theoretical and Applied Physics, African University of Science and Technology (AUST),

P.M.B. 681 Garki, Abuja, Nigeria

${ }^{3}$ Faculty of Natural and Applied Sciences Nile University of Nigeria, Plot 681,

Cadastral Zone C-OO, Research and Institution Area Jabi,

Abuja, 900001 Nigeria

I E-mail: abello@aust.edu.ng

Received July 6, 2020

Revised December 11, 2020

Accepted for publication December 14, 2020

Theoretical study of methyl-ammonium bismuth halide perovskite solar cells, $\left(\mathrm{CH}_{3} \mathrm{NH}_{3}\right)_{3} \mathrm{Bi}_{2} \mathrm{I}_{9}$, was carried out using a one-dimensional Solar Cell Capacitance Simulator (SCAPS-1D) software. The performance of the tested device architectures largely depends on the thickness of the absorbing layer, with the combination of electron transport, and hole transport layers. Thus, the bismuth perovskite absorber layer was optimized by varying the thickness and also, the thicknesses of the different charge-transport materials such as Spiro-OmeTAD, copper (I) oxide $\left(\mathrm{Cu}_{2} \mathrm{O}\right)$, and copper $(\mathrm{I})$ iodide $(\mathrm{CuI})$ as hole transport layer $(\mathrm{HTL})$, and phenyl-C61-butyric acid methyl ester (PCBM), poly(3-hexylthiophene-2,5-diyl) (P3HT), zinc oxide, and titanium dioxide as electron transport layer (ETL). The best performance in terms of the power conversion efficiency (PCE) was recorded for the device with $\mathrm{Cu}_{2} \mathrm{O}$ as the HTL and $\mathrm{ZnO}$ as the ETL with the absorber layer thickness of $200 \mathrm{~nm}$. The working temperature of the device was varied from 295 to $320 \mathrm{~K}$ and the effects of temperature on various device architectures were investigated. Results obtained indication that the efficiency of the bismuth perovskite solar cells can be improved by optimizing the thickness of the absorber layer and utilizing an appropriate combination of HTLs and ETLs.

Keywords: methyl-ammonium bismuth perovskite, SCAPS, HTL, ETL, PCE.

Full text of the paper will appear in journal SEMICONDUCTORS. 